\title{
Original Article (short paper) \\ The acute hypotensive effect of resistance training performed with machines vs free weights in normotensive men
}

\author{
Bruno V. C. da Silva ${ }^{1}$, Mário A. M. Simim² ${ }^{2}$ Lorena Carolina Reis Viegas ${ }^{1}$, Thaís Soares Brígido ${ }^{1}$, Ronaldo Ângelo \\ Dias da Silva ${ }^{1}$, Dustin J. Oranchuk ${ }^{3}$, Gustavo Ribeiro da Mota ${ }^{4}$. \\ ${ }^{1}$ Centro Universitário de Belo Horizonte, UniBH, Department of Environmental, Biological and Health Sciences, Belo Horizonte, MG, Brazil; \\ ${ }^{2}$ Universidade Federal do Ceará, UFC, Research Group in Biodynamic Human Movement, Physical Education Institute and Sports , Fortaleza, CE, \\ Brazil; ${ }^{3}$ Auckland University of Technology I Sports Performance Research Institute New Zealand; ${ }^{4}$ Universidade Federal do Triângulo Mineiro, \\ UFTM, Human Performance and Sport Research Group, Post-Graduation Program in Physical Education, Uberaba, MG, Brazil
}

\begin{abstract}
Aims: To analyze if different resistance training (machine vs free weight) would have different acute hypotensive effect in active and normotensive individuals. Methods: Fifteen male volunteers ( $39.2 \pm 2.5$ years $)$ performed two different resistance exercise protocols, one on machinery and one with free weights for the similar muscle groups and volume (sets x repetitions). Systolic blood pressure (SBP) and diastolic blood pressure (DBP) were measured at rest and during 60 minutes after the sessions. Results: There was no interaction between (treatments $v s$ time) for SBP $\left(F_{70,84}=0.9445, p=0.595\right)$ and $\mathrm{DBP}\left(F_{70,84}=0.5743, p=0.991\right)$. However, significant differences for time for SBP $\left(F_{14,84}=7.058, p=0.001\right)$ and $\operatorname{DBP}\left(F_{14,84}=3.296, p=0.001\right)$, and treatment for $\operatorname{SBP}\left(F_{5,6}=291.1, p=0.001\right)$ and DBP $\left(F_{5,6}=13.29, p=0.003\right)$ were varified. Conclusion: Our findings indicate that both resistance training (machine or free weight) induce a similar hypotensive response for SBP in normotensive men.
\end{abstract}

Keywords: systolic blood pressure, strength training, diastolic blood pressure

\section{Introduction}

Hypertension is a multifaceted syndrome disease which negatively affects millions of people around the world ${ }^{1}$. Therefore, several strategies are adopted for preventing the increase of resting blood pressure. Regular physical activity is a highly effective, low cost strategy for reducing blood pressure without pharmacological intervention ${ }^{2,3}$. The practice of exercises results in acute and chronic decrements not only in systolic blood pressure (SBP), but also diastolic blood pressure (DAP) at rest ${ }^{4}$. Post-exercise hypotension is one of the primary acute responses occurring in the minutes and hours after an exercise session ${ }^{1}$. This acute hypotensive effect is characterized by a reduction in blood pressure when compared to pre-exercise values. Interestingly, there is evidence to suggest that chronic reductions in resting blood pressure could be due to the aggregated effect of several acute exercise sessions (i.e., systemized training) ${ }^{5}$.

At present time, most of the studies examining the acute hypotensive response following exercise have utilized predominantly aerobic exercise such as running, cycling and swimming ${ }^{5}$. However, recent meta-analysis show that resistance training is effective for reducing blood pressure post-exercise ${ }^{1,6}$. Most protocols investigating the effect of resistance training on postexercise blood pressure were designed using weight machines ${ }^{7,8}$. Free-weight resistance exercises activate a greater number of muscle fibers and generate a larger hormonal response when compared to similar movements performed with machines ${ }^{9,10}$. The increased motor-unit recruitment and hormonal response may be favorable when inducing an acute hypotensive response. However, whole-body free-weight resistance exercise may have a transient deleterious effect on cardiovasculature, and potentially decrease baroreflex sensitivity ${ }^{11}$. Thus, it was raised a hypothesis that a difference in resistance training mode (i.e., free weights vs machine) could influence the post-exercise hypotension responses.

In regarding to population investigated, post-exercise hypotensive effects are more pronounced in individuals with hypertension compared with those with normal blood pressure? However, it is necessary to develop studies with normotensive and healthy persons to investigate the influence of different types of exercises on the acute hypotensive response without the influence of aging and related pathologies ${ }^{12}$. Additionally, it could be assumed that alterations in post-exercise blood pressure observed in healthy individuals, would be at least as beneficial in subjects with high blood pressure ${ }^{7}$. Although there is solid evidence on the positive effects of endurance and resistance training, there is a paucity of research comparing post-exercise hypotensive effects of resistance exercise performed with machines or free weights in normotensive subjects. Thus, the objective of this study was to investigate whether the acute hypotensive effect between two protocols (machine vs free weight) of resistance training would be different in active individuals and normotensive individuals. We hypothesized was that free weight exercise would result in higher hypotension effects than machine exercise

\section{Methods}

\section{Subjects}

Fifteen physically active males (age $=39.2 \pm 2.5$; height $=$ $1.76 \pm 0.07 \mathrm{~m}$; body weight $=82.9 \pm 11.5 \mathrm{~kg} ; \mathrm{BMI}=26.4 \pm 3.1$ $\mathrm{Kg} / \mathrm{m}^{2}$ ) volunteered to participate. The subjects had at least six months of experience with exercise protocols similar to those used in the study. Individuals who had diagnosed chronic illnesses or neuromuscular abnormalities were excluded. Individuals were 
also excluded if they had habits such as smoking or excessive ergogenic usage, or were taking medications that could alter blood pressure at rest or during exercise.

The subjects were instructed not to exercise and avoid the caffeine and alcohol intake during the 24 hours preceding each of the studied exercise sessions. Prior to study implementation, participants submitted health screenings where they answered the physical activity readiness questionnaire (PAR-Q) to assess risk factors and symptoms for many chronic cardiovascular, pulmonary and metabolic diseases in order to improve safety during the tests. All volunteers signed an informed consent form, according to the Declaration of Helsinki and the National Health Council for experiments with humans. This study was approved by local Ethics Committee (process number 51.1889).

\section{Anthropometry}

Body mass was measured on a digital scale (trademark Uranus, PS model 180A) with a precision of $100 \mathrm{~g}$ and maximum load of $180 \mathrm{~kg}$, while the height was measured in a wood stadiometer with a precision of $1 \mathrm{~mm}$.

\section{Training Sessions}

The methodological procedures were carried out over two sessions (i.e. exercises performed with machines vs free weights) in a randomized order, at the same time of day with at least 48 hours between sessions. The participants performed two workout protocols: 1) exercises performed on machines guided (Master Equipment $^{\circledR}$, Minas Gerais, Brazil) bench press, guided squat, machine inverse crucifix and guided split squat exercises, 2) exercises performed with free weights: free bench press, free squat, free inverse crucifix and free split squat. Exercises were completed by alternating between limb segments as previous research has demonstrated this practice to be extremely effective in inducing post-exercise hypotensive effects ${ }^{13}$.

Before each protocol, the subjects performed a brief warm-up consisting of 5 minutes of cycling, and 1 set of each exercise using 10 submaximal repetitions at $60 \%$ of the 15 -repititon maximum (RM). During the sessions, the subjects performed 3 sets of 15 repetitions in each exercise. The intensity was determined and adjusted during previous sessions and defined by a weight at which the individual could perform 15 repetitions ${ }^{14}$. An audible metronome (Dolphin ${ }^{\circledR}$ ) was used to control the duration of each repetition. Each repetition lasted four sections, with two second eccentric and concentric phases respectfully. The amplitude determined for all exercises was $90^{\circ}$ from the beginning of the movement. The total training volume was calculated as follows: total training volume $=$ sets $\mathrm{x}$ total repetitions completed ${ }^{15}$.

\section{Blood pressure measurement and heart rate}

Blood pressure (BP) was measured by the auscultatory method utilizing a sphygmomanometer (BD, Brazil) and a stethoscope (Littmann Lightweight, USA). The same evaluator performed all measures in accordance with the criteria regulated by the Brazilian Society of Cardiology ${ }^{16}$. Two measurements were taken on each arm with the average of the two measurements for each arm used for analysis. The intra-class correlation coefficients (ICC) for each variable were: SBP - ICC $=0.75$ $(p=0.001)$ and DBP - ICC $=0.81(p=0.002)$. Heart rate $(\mathrm{HR})$ was recorded by a heart rate monitor (Polar FT7, Finland) in the moment's pre and post-exercise. Participants were comfortably seated in a quiet room for 10 minutes before the initial pre and post-exercise blood pressure and HR measurements. Post-exercise the blood pressure and HR were measured in 15 minute intervals over a 60 minute period.

\section{Statistical Analysis}

The normality of the data was analyzed by the KolmogorovSmirnoff test. Descriptive statistics (mean \pm standard deviations; $95 \%$ confidence intervals) were used to summarize the results of the study variables. Interactions between the treatment (Protocol in machine vs protocol with free weight) and time (rest, $0 \mathrm{~min}, 15 \mathrm{~min} 30 \mathrm{~min} 45 \mathrm{~min}$ and $60 \mathrm{~min}$ ) were analyzed with a two-way repeated measures ANOVA with Tukey post-hoc. The probability of error type I ( $\alpha$ ) of 5\% was used to identify significant differences.

\section{Results}

Table 1 shows the hemodynamic measurements of the volunteers at rest in the machine and free weights resistance exercise protocols.

Table 1: Hemodynamic measurements of the volunteers at rest in the exercise protocols $(n=15)$

\begin{tabular}{lccc}
\hline \multicolumn{1}{c}{ Variables } & $\begin{array}{c}\text { Machine } \\
\text { protocol }\end{array}$ & $\begin{array}{c}\text { Free weights } \\
\text { protocol }\end{array}$ & Effect Size \\
\hline SBP $(\mathrm{mmHg})$ & $116.0 \pm 7.3$ & $116.6 \pm 8.1$ & 0.08 (trivial) \\
$\mathrm{DBP}(\mathrm{mmHg})$ & $78.5 \pm 8.4$ & $80.6 \pm 2.5$ & 0.39 (small) \\
$\mathrm{HR}(\mathrm{bpm})$ & $77.1 \pm 12.1$ & $75.2 \pm 10.3$ & 0.17 (small) \\
\hline
\end{tabular}

Legend: $\mathrm{SBP}=$ systolic blood pressure; $\mathrm{DBP}=$ diastolic blood pressure; $\mathrm{HR}=$ heart rate

No interaction between treatment vs time $\left(F_{(70,84)}=0.9445\right.$, $p=0.595)$ was observed for SBP. However, significant differences for time $\left(F_{(14,84)}=7.058, p<0.001\right)$ and treatment $\left(F_{(5,6)}=291.1\right.$, $p<0.001)$ were observed. Similarly, no significant interaction between (treatment vs tempo) $\left(F_{(70,84)}=0.5743, p=0.991\right)$ for DBP was seen. Significant DBP differences for time $\left(F_{(14,84)}=3.296\right.$, $p=0.003)$ and treatment $\left(F_{(5,6)}=13.29, p=0.003\right)$ were observed.

Figures $1 \mathrm{a}$ and $1 \mathrm{~b}$ summarize blood pressure behavior at rest and post-exercise time points with machine and free 
weight exercise. Immediately following both protocols, SBP (mean differences $=-28.00$; CI95\% $=-33.47$ to -22.53 ; $p<0.0001$ ) and DPB (mean differences $=-9.00 ;$ CI95\% $=$ -15.81 to $-2.192 ; p=0.014$ ) increased significantly compared to rest. However, only SBP was significantly elevated 15 minutes following cessation of exercise (mean differences $=$ -11.33 ; CI95\% $=-16.80$ to $-5.864 ; p=0.014)$. The hypotensive

Figure 1a. The values of SBP in the moments rest, and post-exercise. Denote significates differences between rest and post-exercise $(0$ min.; 15 min.; 45 min. and $60 \mathrm{~min} .{ }^{\#} \mathrm{p}=0.001$ )

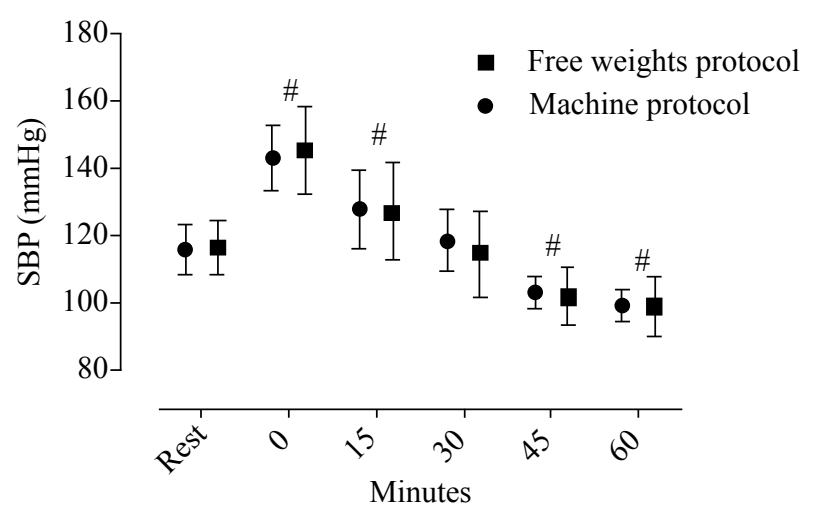

\section{Discussion}

The objective of this study was to investigate the hypotensive effect between two resistance protocols (machine vs free weight), in active normotensive individuals. There was no interaction between treatments X time for SBP and DBP. However, a significant difference in DBP between the free weight and machine protocols was observed 30 minutes after the exercise sessions. The SBP and DBP increased significantly immediately after both protocols. Only SBP was significantly $(+12 \mathrm{~mm} \mathrm{Hg}$ for machine and $+10 \mathrm{~mm} \mathrm{Hg}$ for free weight) elevated 15 minutes post-workout compared with baseline. The hypotensive effect in SBP was observed $45(-13 \mathrm{~mm} \mathrm{Hg}$ for machine and $-20 \mathrm{~mm}$ $\mathrm{Hg}$ for free weight) and 60 minutes $(-17 \mathrm{~mm} \mathrm{Hg}$ for machine and $-20 \mathrm{~mm} \mathrm{Hg}$ for free weight) post-exercises.

A recent meta-analysis reported that resistance training is able to induce hypotensive effects comparable to endurance training ${ }^{6}$. This reduction in blood pressure can occur in both healthy and hypertensive individuals ${ }^{13}$ and can be observed in both systolic and diastolic phases ${ }^{6}$. However, blood pressure reduction occurred exclusively in the SBP phase in the current study. This behavior also has been reported in other studies examining ${ }^{17,18}$. The lack of change in DBP may be justified by the pre-exercise value, since the post-effort values are directly related with the pre-exercise values $^{19}$. For this reason, hypertensive subjects would present a greater absolute reduction in pressure values than normotensive ones ${ }^{19}$. Interestingly, although we did not find a hypotensive effects for DBP, a significant difference between machine and free weight conditions was observed at $30 \mathrm{~min}$ post-exercise. However, the exact causes of this response is unclear. effect was observed for SBP after 45 minutes (mean differences $=-41.67$; CI95\% $=36.20$ to $47.14 ; p<0.001)$ and 60 minutes independent of protocol (mean differences $=$ 45.00; CI95\% $=39.53$ to $50.47 ; p<0.0001)$. A significant difference was observed between free weights and machine exercise 30 minutes post exercise (mean differences $=4.00$; CI95\% $=78.21$ to $83.13 ; p=0.030)$.

Figure $1 \mathrm{~b}$. The values of DBP in the moments rest, and post-exercise. At $0 \min ^{*} \mathrm{p}=0.014$ and between protocols $* \mathrm{p}=0.03$

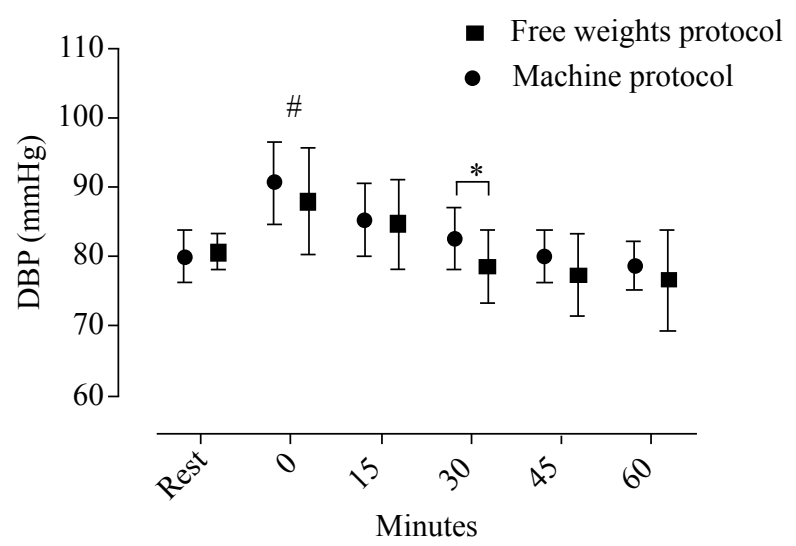

Regarding the blood pressure response immediately after resistance exercise, both the SBP and DBP were significantly higher comparing to the pre-exercise moment. Increases of 27 $\mathrm{mm} \mathrm{Hg} \mathrm{(23.7 \% ),} \mathrm{and} 30 \mathrm{~mm} \mathrm{Hg} \mathrm{(25 \% )} \mathrm{for} \mathrm{SBP,} \mathrm{and} 11 \mathrm{~mm}$ $\mathrm{Hg}(13.3 \%)$ and $10 \mathrm{~mm} \mathrm{Hg}$ (12.5\%) for DBP were observed following machine and free weight protocols respectively. These results are similar to those reported in the literature ${ }^{19,20}$. This elevated post-exercise blood pressure response may be explained by an increase in peripheral fatigue causing the activation of peripheral chemoreceptors ${ }^{19,21}$.

The time to observe a hypotensive post-exercise response seems to vary between studies. Our results demonstrated that the SBP showed a significant reduction at 45 (-11\% for machine) and $(-17 \%$ for free weight) and 60 minutes of recovery $(-14 \%$ for machine) and $-(17 . \%$ for free weight $)$. Maior, Azevedo, Berton, Gutiérrez, Simão ${ }^{17}$ conduced a similar study in which post-exercise hypotension occurred with 30 and 40 minutes, with the greatest variation reported at 40 minutes (5.2\%). Dias, Simão and Novaes ${ }^{22}$ observed a significant decrease in blood pressure at 40 minutes, which lasted until 90 minutes post-resistance training utilizing the upper and lower limbs.

The mechanisms involved in the post-exercise hypotensive effect are still not completely elucidated. The different physiological pathways acting in isolation or in combination may contribute to the difficulty in explaining the post-exercise hypotensive phenomenon ${ }^{19}$. The reasons for the post-exercise blood pressure decrease are thought to be the result of a decrease in peripheral vascular resistance (8). This phenomenon may be related to several factors. These potential factors include vasodilation caused by physical exercise, reduction in sympathetic nervous activity, 
alterations in the functioning of the arterial and cardiopulmonary baroreceptors and the thermoregulatory response caused by exercise and increased serotonin secretion ${ }^{23}$. In addition, a greater release of nitric oxide and a lower adrenergic discharge could also play a role in blood pressure attenuation ${ }^{24,25}$.

Another factor that may have influenced our results is the magnitude of muscle mass involved in the exercises. However, muscle size in the machine and free weight protocols was very similar. Santos, Dias, Santos, Goldoni, Novaes, Simão ${ }^{26}$ compared the post-effort hypotensive response between leg press and biceps Scott curl exercises performed with two minutes intervals. Santos, Dias, Santos, Goldoni, Novaes, Simão ${ }^{26}$ reported that the amount of muscle mass significantly influenced the post-exercise hypotension response. In contrast, D'Assunção, Daltro, Simão, Polito, Monteiro ${ }^{27}$ compared the acute cardiovascular responses of exercises utilizing the elbow flexors or knee extensors and found no significant difference for SBP or DPB between exercises. D'Assunção, Daltro, Simão, Polito, Monteiro ${ }^{27}$ results demonstrate that the amount of the muscle mass involved may not always influence the cardiovascular responses ${ }^{27}$. However, the different results reported by Santos et al. ${ }^{26}$ and D'Assunção et al's. ${ }^{27}$ can be justified by the fact that one utilized the multi-articular leg press, while the other used a mono-articular leg extension machine.

Blood pressure behavior following resistance exercise presents conflicting results, probably due to the different forms of manipulation of training variables (i.e. intensity, volume, tempo, rest etc.) and training methods. Additionally, environment and life-style factors (i.e. traffic, work, sleep etc.) as well as the time of day that BP is measured may influence hemodynamic responses $^{28}$. These factors may be considered limitations in the present study, since no sleep or daily activity monitoring took place. However, the participant's routine was not altered during experimental procedure with the exception of forbidding intense exercise and caffeine or BP effecting medication 48-hours before each exercise session. Our ICC values for BP confirm that the previously mentioned factors did not influence the BP responses. Accordingly, it was demonstrated that there is no influence of activity on BP response ${ }^{28}$. An additional limitation could be that we investigated BP responses in normotensive and not hypertensive subjects. However, as stated anteriorly, our purpose was to investigate the hypotension without the influence of aging and related pathologies.

The results of our study suggest that resistance training performed with machines or free weights are equally attractive strategies for inducing acute hypotensive effects. Resistance exercise is commonly prescribed to individuals without known hypertension to enhance health. The results of the present study should be considered when designing resistance training programs for cardiovascular health benefits. While both methods were equally effective in acutely reducing blood pressure, free weights often carry a considerably lower financial burden. Clinicians can feel confident utilizing free weights or machines depending the capabilities of the patient and the equipment available. Additional research is needed to delineate the chronic effects of resistance training performed with machines or free weights.

\section{Conclusion}

The results of this study indicate that hypotensive effects in normotensive subjects are independent if resistance training is performed with machines or free weight.

\section{References}

1. Law M, Morris J, Wald N. Use of blood pressure lowering drugs in the prevention of cardiovascular disease: meta-analysis of 147 randomised trials in the context of expectations from prospective epidemiological studies. BMJ. 2009;338:1-19.

2. Casonatto J, Polito MD. Hipotensão pós-exercício aeróbio: uma revisão sistemática Post-exercisehypotension\&58; a systematic review. Rev Bras Med Esport. 2009;15(2):151-7.

3. Maior AS, Paixão RC, Marocolo I, Freitas DGS, Mota GR, Marocolo M. Acute responses of rate pressure product in sets of resistance exercise. Med Sport. 2014;18(1):36-41.

4. de Fátima Monteiro M, Filho DCS. Exercício físico e o controle da pressão arterial. Rev Bras Med Esport. 2004;10(6):513-6.

5. Collins R, MacMahon S. Blood pressure, antihypertensive drug treatment and the risks of stroke and of coronary heart disease. Br Med Bull. 1994;50(2):272-98.

6. MacDonald HV, Johnson BT, Huedo-Medina TB, Livingston J, Forsyth KC, Kraemer WJ, et al. Dynamic Resistance Training as Stand-Alone Antihypertensive Lifestyle Therapy: A MetaAnalysis. J Am Heart Assoc. 2016;5(10):1-34

7. Fisher MM. The effect of resistance exercise on recovery blood pressure in normotensive and borderline hypertensive women. $\mathrm{J}$ Strength Cond Res. 2001;15(2):210-6.

8. Polito MD, Farinatti PT. The effects of muscle mass and number of sets during resistance exercise on postexercise hypotension. $\mathrm{J}$ Strength Cond Res. 2009;23(8):2351-7.

9. Shaner AA, Vingren JL, Hatfield DL, Budnar Jr RG, Duplanty AA, Hill DW. The acute hormonal response to free weight and machine weight resistance exercise. J Strength Cond Res. 2014;28(4):1032-40.

10. Schwanbeck S, Chilibeck PD, Binsted G. A comparison of free weight squat to Smith machine squat using electromyography. J Strength Cond Res. 2009;23(9):2588-91.

11. Kingsley JD, Mayo X, Tai YL, Fennell C. Arterial Stiffness and autonomic modulation after free-weight resistance exercises in resistance trained individuals. J Strength Cond Res. 2016;30(12):3373-80.

12. Pardono E, Fernandes MdO, Azevêdo LM, Almeida JAd, Mota MR, Simões HG. Post-exercise hypotension of normotensive young men through track running sessions. Rev bras med esporte. 2015;21(3):192-5.

13. Jannig PR, Cardoso AC, Fleischmann E, Coelho CW, Carvalho Td. Influência da ordem de execução de exercícios resistidos na hipotensão pós-exercício em idosos hipertensos. Rev bras med esporte. 2009:338-41.

14. Tibana RA, Prestes J, da Cunha Nascimento D, Martins OV, De Santana FS, Balsamo S. Higher muscle performance in adolescents compared with adults after a resistance training session with different rest intervals. J Strength Cond Res. 2012;26(4):1027-32.

15. Scott BR, Duthie GM, Thornton HR, Dascombe BJ. Training monitoring for resistance exercise: theory and applications. Sports Med. 2016;46(5):687-98. 
16. Malachias MVB, Póvoa R, Nogueira A, Souza D, Costa L, Magalhães M. 7th Brazilian Guideline of Arterial Hypertension: chapter 3-clinical and complementary assessment. Arq Bras Cardiol. 2016;107(3):14-7.

17. Maior AS, Azevedo M, Berton D, Gutiérrez C, Simão R. Influência de distintas recuperações entre as séries no efeito hipotensivo após uma sessão de treinamento de força. Rev Socerj. 2007;20(6):416-22.

18. Terra DF, Mota MR, Rabelo HT, Bezerra LMA, Lima RM, Ribeiro AG, et al. Redução da pressão arterial e do duplo produto de repouso após treinamento resistido em idosas hipertensas. Arq Bras Cardiol. 2008;91(5):299-305.

19. Mediano MFF, Paravidino V, Simão R, Pontes FL, Polito MD. Comportamento subagudo da pressão arterial após o treinamento de força em hipertensos controlados. Rev Bras Med Esporte. 2005;11(6):337-40.

20. Bermon S, Rama D, Dolisi C. Cardiovascular tolerance of healthy elderly subjects to weight-lifting exercises. Med Sci Sports Exerc. 2000;32(11):1845-8.

21. Carrington C, White M. Exercise $\square$ induced muscle chemoreflex modulation of spontaneous baroreflex sensitivity in man. The Journal of physiology. 2001;536(3):957-62.

22. Dias I, Simão R, Novaes J. A influência dos exercícios resistidos nos diferentes grupamentos musculares sobre a pressão arterial. Fit Perf J. 2007;6(2).

23. Halliwill JR. Mechanisms and clinical implications of postexercise hypotension in humans. Exercise and sport sciences reviews. 2001;29(2):65-70.

24. Halliwill JR, Minson CT, Joyner MJ. Effect of systemic nitric oxide synthase inhibition on postexercise hypotension in humans. J Appl Physiol. 2000;89(5):1830-6.
25. Halliwill JR, Dinenno FA, Dietz NM. $\alpha \square$ Adrenergic Vascular Responsiveness during Postexercise Hypotension in Humans. J Physiol. 2003;550(1):279-86.

26. Santos EMR, Dias IBF, Santos M, Goldoni M, Novaes J, Simão Jr RF. Comportamento agudo da pressão arterial após exercícios resistidos para pequenos e grandes grupamentos musculares. Arquivos em Movimento. 2007;3(1):18-28.

27. D’Assunção W, Daltro M, Simão R, Polito M, Monteiro W. Respostas cardiovasculares agudas no treinamento de força conduzido em exercícios para grandes e pequenos grupamentos musculares. Rev Bras Med Esporte. 2007;13(2):118-22.

28. Clark L, Denby L, Pregibon D, Harshfield GA, Pickering T, Blank $\mathrm{S}$, et al. A quantitative analysis of the effects of activity and time of day on the diurnal variations of blood pressure. J Chronic Dis. 1987;40(7):671-81

\section{Corresponding author}

Bruno V. C. da Silva

Centro Universitário de Belo Horizonte, UNI-BH, Av. Mário Werneck, 1685, Estoril, Zip: 30455-610, Belo Horizonte, MG. Brazil.

Email: brunobjjbh@gmail.com

Manuscript received on December 24, 2017

Manuscript accepted on May 28, 2018

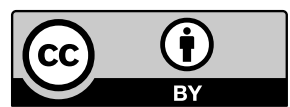

Motriz. The Journal of Physical Education. UNESP. Rio Claro, SP, Brazil - eISSN: 1980-6574 - under a license Creative Commons - Version 4.0 